\title{
Sustainable Tropical Cities: A Scoping Review of Multidisciplinary Methods for Urban Planning
}

\author{
Taha Chaiechi
}

https://orcid.org/0000-0002-9976-972X

James Cook University, Australia

\begin{abstract}
Most studies of urban sustainability are characterised by traditional approaches focusing on environmental aspects. These studies often neglect the influence of issues such as governance, society, culture, and geography. Multidisciplinary contributions remain poorly understood in this field, although evidence suggests that regional, geographical and socio-cultural factors are essential in shaping sustainable urban planning. Following Arksey and O'Malley's (2005) scoping approach to literature reviews, this article provides a mapping technique and a scoping review to show the extent and nature of applied methodologies in the field of urban sustainability. The paper finds that there is a global need for sustainable urban planning through innovative multidisciplinary approaches. The paper calls for an accelerated knowledge creation in the field of urban development based on climate-classifications, socio-economic information, and locational characteristics. It particularly notes the need for research in the Tropics where distinct socio-economic dynamics and climate conditions have specific impacts on sustainable urban planning.
\end{abstract}

Keywords: sustainable cities, practical methods, multidisciplinary approaches, sustainable urban development, urban sustainability assessment, tropical cities

eTropic: electronic journal of studies in the tropics publishes new research from arts, humanities, social sciences and allied fields on the variety and interrelatedness of nature, culture, and society in the tropics. Published by James Cook University, a leading research institution on critical issues facing the worlds' Tropics. Free open access, Scopus Listed, Scimago Q2. Indexed in: Google Scholar, DOAJ, Crossref, Ulrich's, SHERPA/RoMEO, Pandora. ISSN 1448-2940. Creative Commons CC BY 4.0 free to download, save and reproduce. To cite, include: Author(s), Title, eTropic, volume, issue, year, pages and DOI: http://dx.doi.org/10.25120/etropic.19.2.2020.3743 
eTropic 19.2 (2020) Special Issue: Sustainable Tropical Urbanism

$\mathrm{P}$ opulation movements into cities have accelerated over the past few decades, with more than half of the world's population now living in urban areas. This rapid urbanisation places an enormous demand on infrastructure, service sectors, and natural environments, including land. Swiftly expanding cities and growing population necessitate city-level adaptations of sustainable development practices. While adaptation rates vary from city to city, most growing cities are starting to demonstrate commitments to integrate sustainable development goals into their planning frameworks.

At the same time, methodological diversity of urban development studies has also been expanding due to the growing interest of various academic disciplines in sustainable urban and peri-urban development. However, the research community often struggles with harnessing wicked problems with value conflicts in multistakeholder initiatives. Academics acknowledge the multidisciplinary nature of sustainability research, but discussions of appropriate methodologies for sustainable development remain fragmented and lack interdisciplinary perspectives. Evidence suggests there is a knowledge gap in practical frameworks to assess methods for urban sustainability. This paper asserts that research in the field of urban development will benefit enormously from developing multidisciplinary methodologies because of the depth and breadth these efforts enfold.

Through adopting a scoping review methodology (see Arksey \& 'O'Malley, 2005), the paper maps existing literature across a wide range of studies in the field of urban development. The primary aim is to provide an overview of existing research evidence without producing a summary answer to a particular research question. To that end, this review offers an opportunity to identify key methodologies used in urban development studies, as well as their strengths and limitations. Furthermore, to understand the project of multidisciplinary endeavour, the review explores the need to improve conceptual understanding of the interconnections between sustainable cities and development (Wilkerson et al., 2018). It also shows the importance of multidimensional integration of social/cultural, economic and environmental/climate factors in developing sustainable urban models and planning policies.

Finally, the paper reflects on the suitability and relevance of available methods for urban research in the Tropics where there are distinct differences in terms of socioeconomic dynamics and climate. Methods of sustainable urban planning that are widely used in the temperate zone might be inappropriate to the conditions of the Tropics. For instance, according to the State of the Tropics report (2014), tropical economies are growing almost $20 \%$ faster than the rest of the world. Furthermore, 
$40 \%$ of the world's population lives in the tropics. ${ }^{1}$ At the current pace, the projection shows this rate will be $50 \%$ by 2050 (State of the Tropics, 2014; Harding et al., 2016). At the same time, the growth of tropical economies and the accelerating demographics have resulted in swift expansion of tropical cities. Additionally, the Group of Twenty (G20) (with almost half of their members located either entirely or partially in the tropical zone) has committed to stimulating sustainable and balanced economic growth in the tropical economies (Hockey, 2014). With such arguments accumulating, examining a blend of different methods used in a range of academic disciplines from across the globe would help us better understand the multidimensional nature of sustainable urban development research.

\section{Methods}

To investigate the extent and variety of available methods, and the influence of multidisciplinary approaches in urban development studies, this paper follows Arksey and O'Malley (2005) in establishing a broad question as a guide in shaping the search strategy. Accordingly, to pre-define the objectives, methods and reporting strategies, an a priori protocol was developed. The protocol detailed the guiding question, specific inclusion and exclusion criteria (Table 1 eligibility criteria), secondary screening search terms, and reporting and presentation techniques.

Table 1 Eligibility Criteria

\begin{tabular}{|c|c|c|}
\hline Criterion & Inclusion & Exclusion \\
\hline Publication Year & $2001-2020$ & Studies outside this period \\
\hline Search Language & English & Non-English literature \\
\hline Type of literature & $\begin{array}{l}\text { Peer-reviewed original research, conference } \\
\text { proceedings, working papers, books, and } \\
\text { governmental reports }\end{array}$ & Non-scholarly sources \\
\hline Concept & $\begin{array}{l}\text { Studies that discuss dimensions of Sustainable } \\
\text { Development and provide practical and transparent } \\
\text { evaluation frameworks }\end{array}$ & Studies without practical focus \\
\hline Coverage & Allowed great coverage of academic disciplines & nil \\
\hline Relevance & Title and abstract relevant to the guiding question & Irrelevant titles and abstracts \\
\hline
\end{tabular}

The initial guiding question was "Are socio-economic factors considered key measurable indicators in determining sustainable city frameworks, despite rarely being addressed in planning policies?" The search strategy involved utilising search engines such as Google Scholar and James Cook University's library databases. The aim was

\footnotetext{
${ }^{1}$ https://worldpopulationreview.com/countries/tropical-countries/
} 
eTropic 19.2 (2020) Special Issue: Sustainable Tropical Urbanism

to formulate a guiding question to cover an adequate range of parameters that did not result in an unmanageable quantity of articles, and which transcended a range of specific disciplines but also reduced the probability of missing essential articles. The eligibility criteria were initially based on the relevance of titles and abstracts to the guiding question. One of the primary inclusion criteria was the time-span. While academic literature about the importance of cities and their economic and social benefits date back at least a century, the concept of sustainable development only reached international recognition in 1992 during the United Nations Conference on Environment and Development (UNCED) 'Earth Summit' in Rio de Janeiro. In 2002, to mark the 10th anniversary, the UNCED 'World Summit on Sustainable Development' was held in Johannesburg. This summit, in particular, was a defining moment for sustainable development. Accordingly, the time-span of 2001-2020 was deemed appropriate for this study.

Title and abstract screening was performed by the author. The primary search was conducted manually, using the guiding question and the eligibility criteria, which resulted in the selection of 195 studies. A staged approach for evaluating and analysing the search results was adopted (see Figure 1). Following the second round of screening, based on exclusion criteria and removal of duplicated articles, 98 studies met the eligibility criterial based on the relevance to the guiding question. Five studies could not be obtained and were therefore removed from the review; ten others were removed from consideration following full-text screening. Upon finalisation of the selection process, 83 full-text studies were included in the final evaluation.

Figure 1 A priori protocol

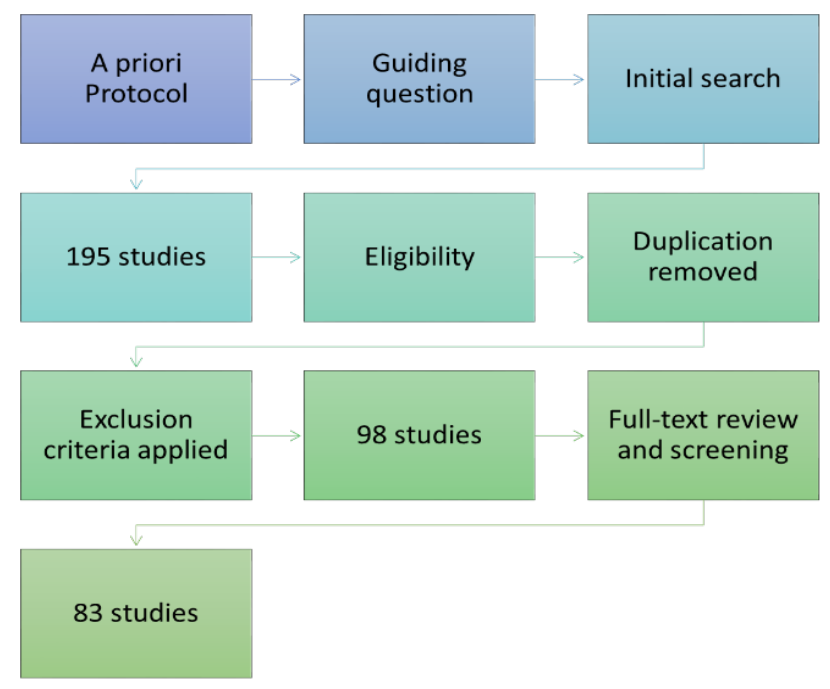

Illustration of the a priori protocol and study selection process 
eTropic 19.2 (2020) Special Issue: Sustainable Tropical Urbanism

\section{Results}

The next step was charting the data to create a descriptive summary of information such as disciplinary groups, year of publication, methods used, and a brief discussion on the commonality between different approaches. The selected studies were assessed for evidence of the parallel existence of discrete knowledge sources from a variety of disciplines. Figure 2 illustrates the percentage of instances where disciplinary areas appear in the selected studies.

\section{Figure 2 Disciplines identified in reviewed studies}

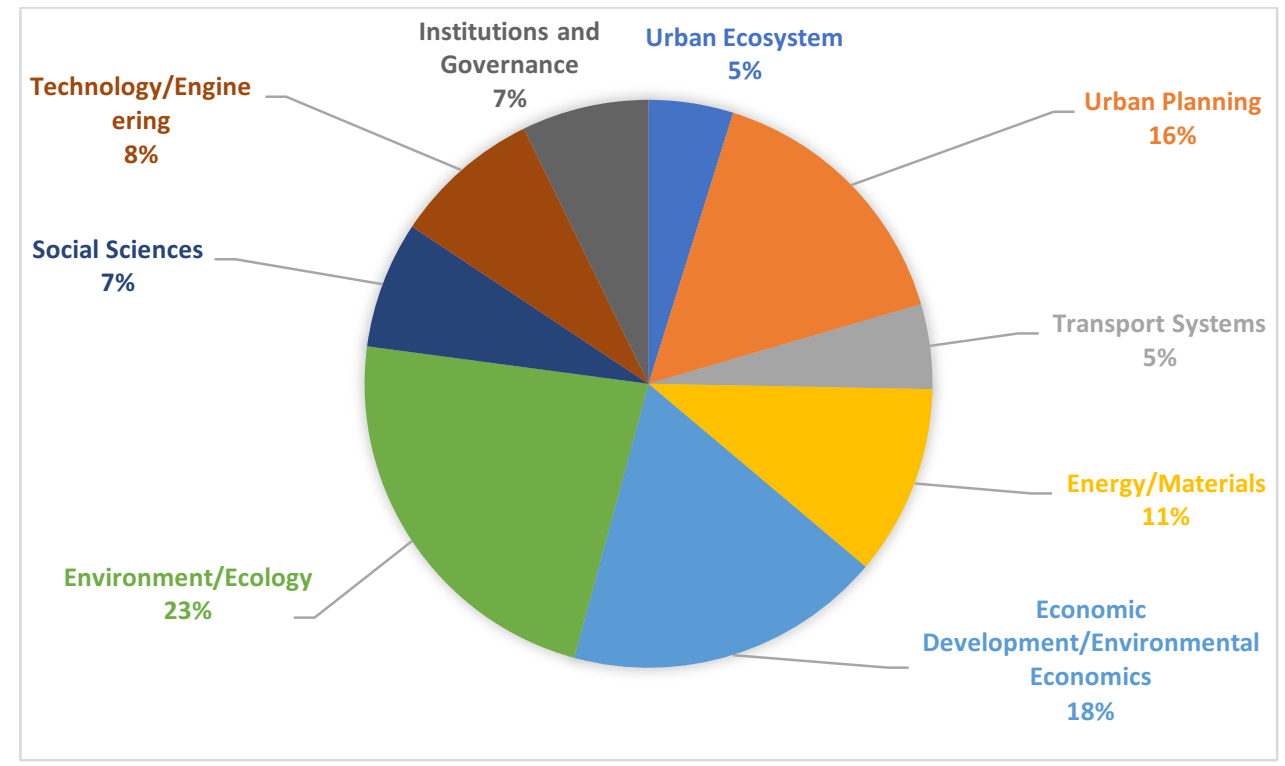

As observed in Figure 2, the three major disciplines of the literature are Environment/ Ecology (comprising $23 \%$ of the selected studies), Economic Development/ Environmental Economics (18\%), and Urban Planning (16\%). Following these three disciplinary areas are Energy/Material (11\%) and Technology/Engineering (8\%). While current pressing issues faced by researchers from environment, economics, and planning disciplines are somewhat interconnected, their collective attention to the topic area indicates the increasing importance of a multidisciplinary approach to urban sustainability. The Institutions and Governance discipline accounts for $7 \%$ of the selected studies that mainly look at the existing governance arrangements concerning the nature and growth of urban sustainability. Other identified disciplines include Social Sciences (7\%), Transport Systems (5\%), and Urban Ecosystems (5\%), in descending order of occurrence in the search results. 
eTropic 19.2 (2020) Special Issue: Sustainable Tropical Urbanism

The review further looked at the geographical scope of the selected studies, and the methods used. Overall, 38 countries were identified in the collection. As demonstrated in Figure 3, the collection includes high coverage of articles in countries like China, the USA, Japan, and Sweden, and low coverage in other countries. The frequency of applied methods is also evidenced in Figure 3.

Figure 3 Countries of focus and the methodologies used in the included studies

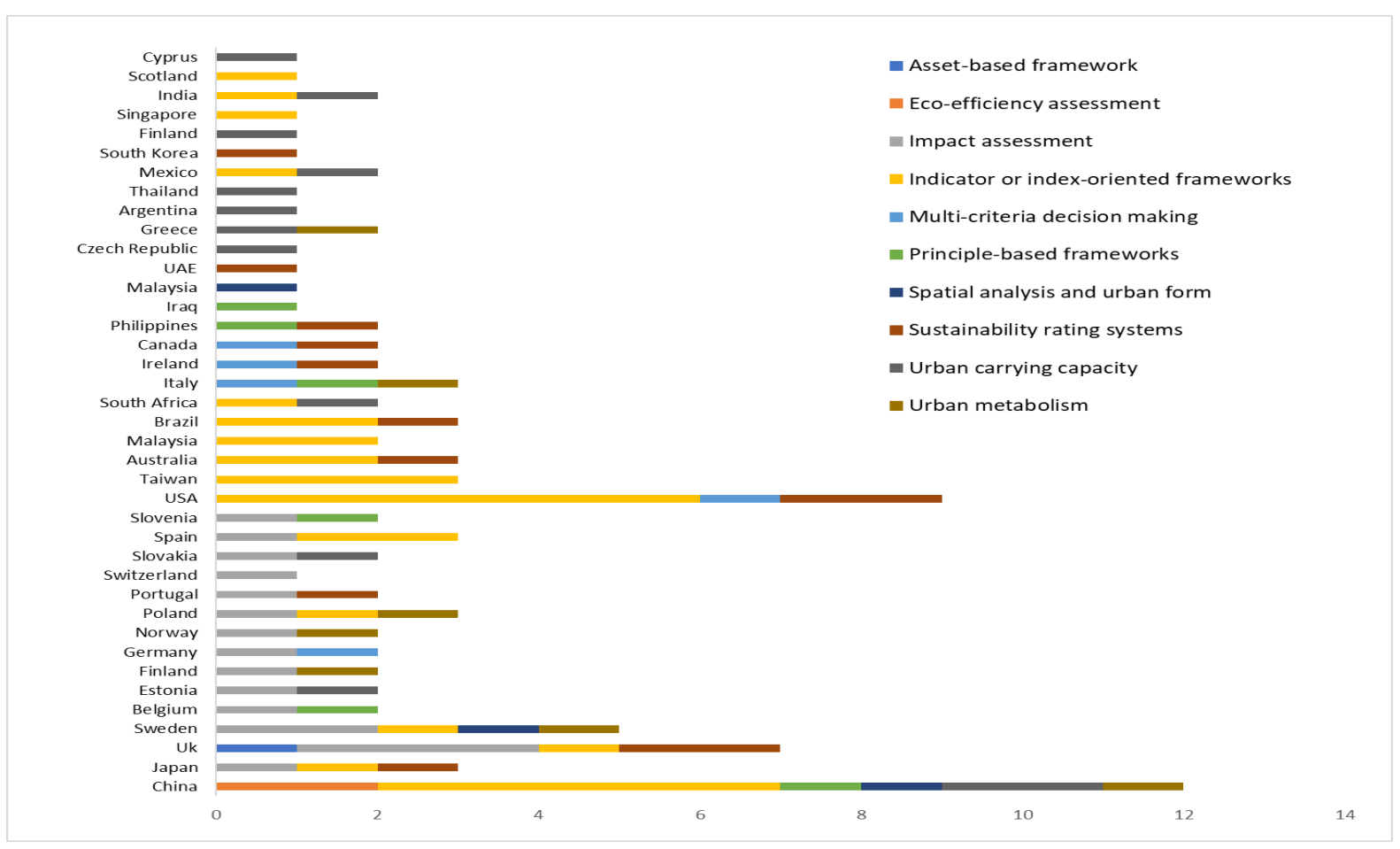

From the pool of 38 countries, five countries are in the tropics, with another five countries geographically located in both tropical and subtropical zones. Seven other countries are partly situated in the subtropical zone, and the remaining 21 countries are located in temperate and frigid zones. The initial analysis showed that urban sustainability studies are increasingly becoming a trending practice in the literature as the methodological approaches diversify; however, our sample of selected studies suggests a lack of well-developed methodologies with a focus on the Tropics. This observation is particularly important as the research indicates that climatic classifications and geographical locations influence the characteristics of urban systems (Emilsson \& Sang, 2017; Fitria et al., 2019). Moreover, evidence suggests that capital and metropolitan cities with tropical climates are more vulnerable to the effects of climate change, where hot and humid conditions create extra challenges (State of the Tropics, 2014; Oppermann, et al., 2017). Subsequently, this observation calls for fast-track knowledge creation and collation of multidisciplinary evidence in the field of sustainability in tropical cities. 
eTropic 19.2 (2020) Special Issue: Sustainable Tropical Urbanism

To audit the data further, the research charted year of publication against primary applied methods in the selected studies, as demonstrated in Figure 4. The figure shows a significant increase in the number of publications in the field during the sampling period.

Figure 4 Articles included in the review by publication year and methods applied

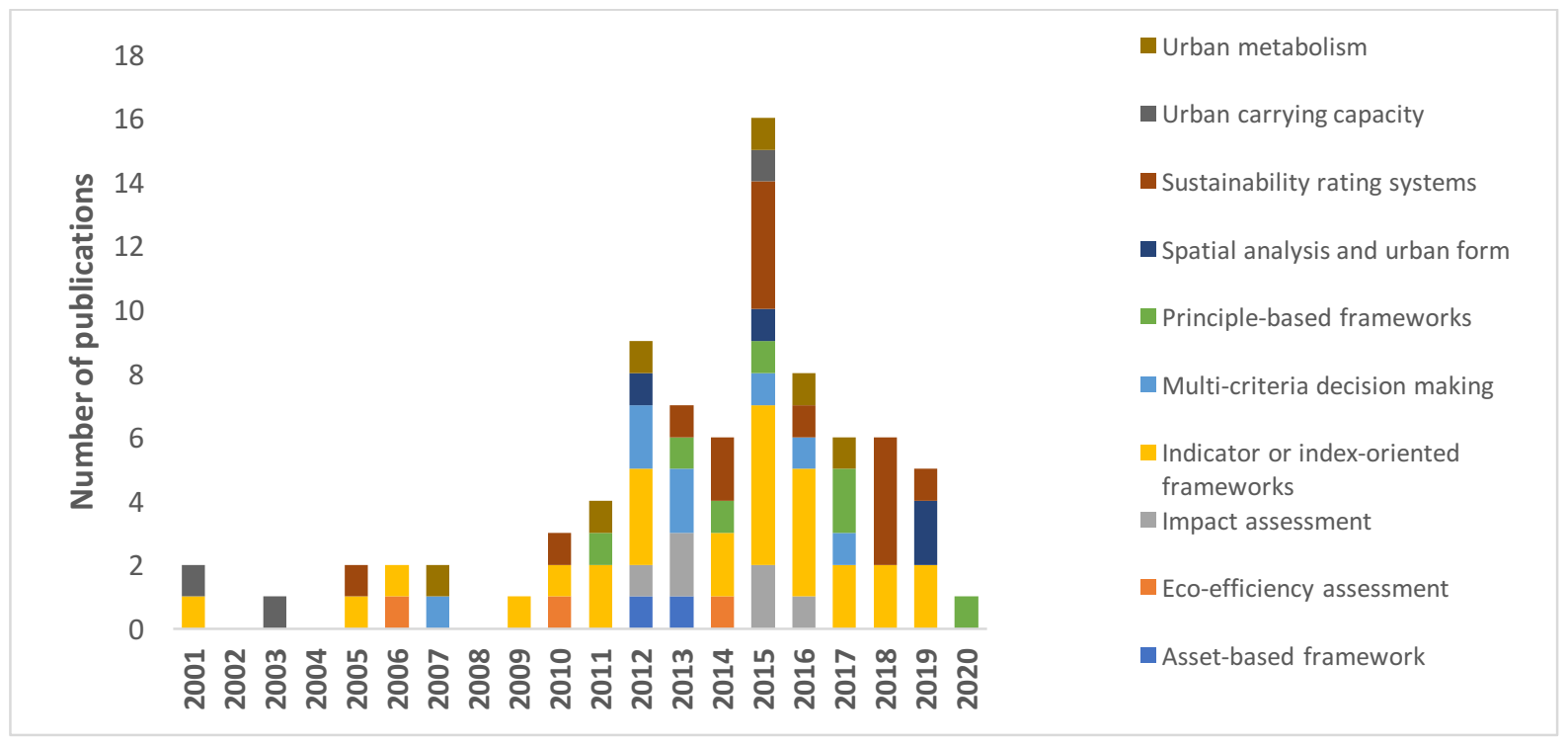

The evolution of urban sustainability studies in the collected sample (as depicted in Figure 4) shows that the increase in the application of various contemporary methods began in 2010. The most frequently applied methods in the sample include sustainability rating systems, the asset-based framework (primarily used by Mathie \& Cunningham, 2003; Eyles, 2007; and appearing later in studies such as Chang et al., 2018), indicator or index-oriented framework, and the multi-criteria decision-making approach. Figure 4 also indicates that the application of these methods in urban studies reached a peak in 2012 and again in 2015, with a slow decline afterwards. The timeline shows that the indicator or index-oriented framework was the most consistently applied method over the period 2001-2020.

A summary of the methods used in the final sample is shown in Figure 5. The summary reveals that the indicator or index-oriented framework has a total of 27 applications in the sample, followed by sustainability rating systems with 15 applications, multi-criteria decision analysis and principle-based frameworks with eight applications each, urban metabolism with seven, impact assessment with six, etc. These most frequently applied methods are discussed below. 
eTropic 19.2 (2020) Special Issue: Sustainable Tropical Urbanism

Figure 5 Summary of methods applied in studies reviewed

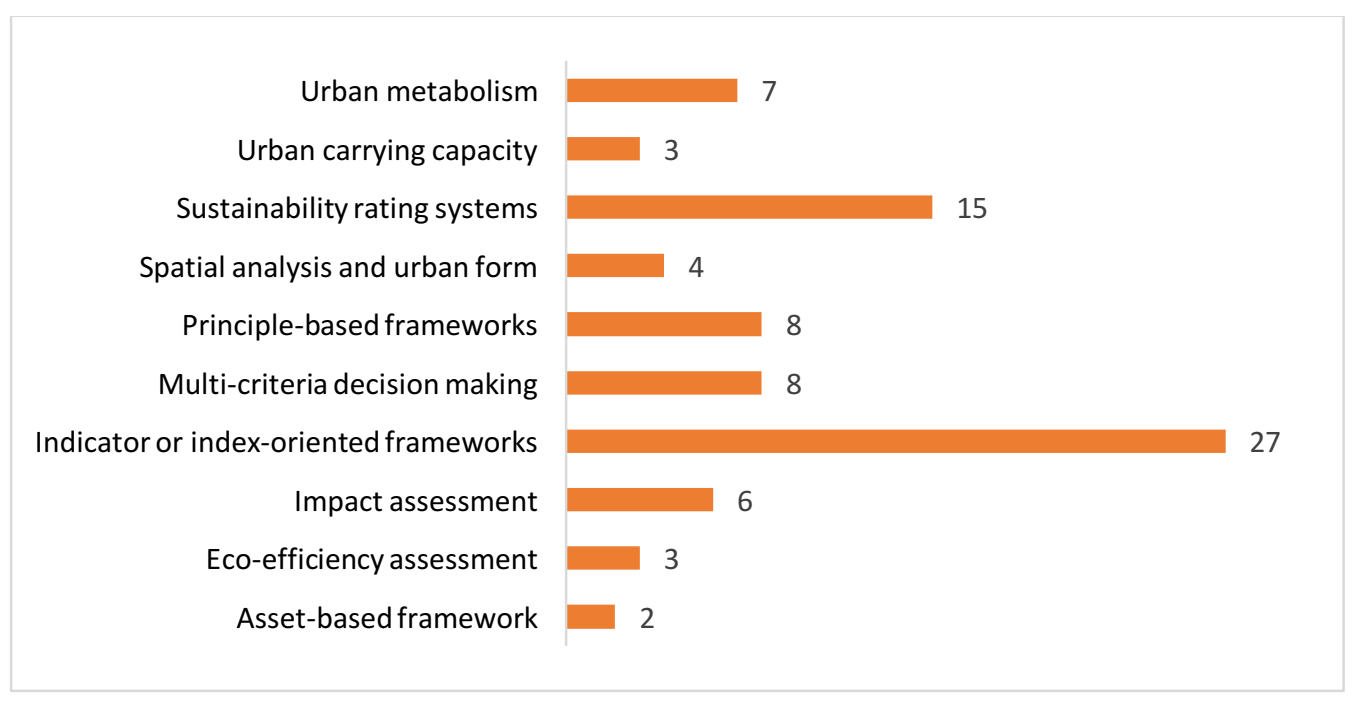

\section{Indicator or Index-Oriented Frameworks}

Studies applying the indicator or index-oriented framework used performance metrics that are primarily indicators or indices designed to measure sustainability. These studies include the following: McLaren (1996), Atkisson and Hatcher (2001), Browne et al. (2005), Olalla-Tarraga (2006), Masnavi (2007), Scipioni et al. (2008), Ciegis et al. (2009), Shen et al. (2011), Davidson et al. (2012), Michael et al. (2014), BraulioGonzalo et al. (2015), Tran (2016), Lutzkendorf \& Balouktsi (2017), Niemeijer \& de Groot (2008), Mori \& Christodoulou (2012), Mori \& Yamashita (2015), Ries et al. (2016) and Baroghi et al. (2018).

The indicator/index-oriented framework is a conceptual structure that is defined based on the principles of sustainability and it is often used to facilitate the identification, development and understanding of contributing factors (see, for example Niemeijer \& de Groot, 2008; Shen et al., 2011). The indicators denote variables in the models, and values of these indicators provide information about the circumstances of trajectories of an under-study system. The indicators are used with an established point of reference (benchmark) or threshold to represent a goal or the desired point. These thresholds are established based on the relevant knowledge of the selected social or environmental systems or shared understanding of the community in which the system is involved. Therefore, indicators used in sustainability studies are particularly suitable for delivering useful information on the mechanism and the driving forces behind socioenvironmental systems. 
eTropic 19.2 (2020) Special Issue: Sustainable Tropical Urbanism

Criteria for selecting these indicators begin by determining essential aspects of a (socio-environmental) monitoring system and identifying variables that estimate the extent of sustainability or the performance of factors necessary to achieve a certain threshold of sustainability. An example is a study around 'Bellagio Principles' edited by Hardi and Zdan (1997) published by the International Institute of Sustainable Development (IISD). The study synthesised insights from existing practical efforts to bring together a set of global measures as a guideline to develop assessment tools and evaluate sustainability progress in different countries.

The Bellagio Principles (Hardi \& Zdan, 1997) help improve assessment activities and processes across the globe. The ten principles include: establishing a clear vision and a set of feasible goals (Principle 1), content and dimensions of assessments and identification of priorities (Principles 2-5), steps and process of evaluation (Principles $6-8$ ), and urgency and continuity of the assessment (Principles 9 and 10). These principles together provide a conceptual sustainability indicator framework for all three stages of indicator selection, assessment development, and interpretation of results.

The most frequently documented set of indicators in the literature cover several aspects of sustainability and their compound internal interactions (e.g. Mathi \& Cunningham, 2003; Shen et al., 2011; Mischen et al., 2019; Zhai et al., 2019). Nevertheless, the literature seems to be consistent in advising that these indicators should be informative, for instance, Ciegis et al. (2009), easy to gather and easy to understand (Ding et al., 2015), policy-related (Munier, 2011), and predictive (Niemeijer $\&$ de Groot, 2008). Studies are also persistent in noting that the methods used to aggregate or produce these indicators should also be transparent and unbiased, for instance Lamorgese and Geneletti (2013), Niemeijer and de Groot (2008), Michael et al. (2014). Together, these studies provide a robust theoretical basis for the indicator or index-based frameworks. More importantly, as Shen et al. (2011) argue, the indicator systems are required to accommodate the sustainability needs of a city where it is being implemented.

Another strand of studies has branched out from the application of the matrix-based system to the use of linear programming in the procedure of selecting sustainability indicators, for instance, Munier (2011). Bockstaller \& Girardin (2003) provide an early analysis that mainly focused on conceptual validation during the indicator selection process. The use of indicators has equally been extended from urban assessment to indicators of the Sustainable Development Goals (SDGs) as evidenced in Zinkernagel et al. (2018) and Porio (2015); mobility indicators as shown in Stojanovski (2019); and the housing index as seen, for example, in Siqueira-Gay et al. (2019). 
eTropic 19.2 (2020) Special Issue: Sustainable Tropical Urbanism

In early studies such as van Dijk and Mingshun (2005), indicators were selected from a sustainability indicator database through extensive consultation with academic and professional experts using a pre-coded questionnaire. Ciegis et al. (2009) reviewed the overall concept of sustainability indicators and principles of sustainable development. They concluded that since societies are regularly subjected to change and evolving interactions, sustainable indicators must be continually revised and corrected. They also argued that when developing a set of sustainability indicators, all social, economic, environmental, governance, and cultural dimensions must be included in the set of indicators. Accordingly, the objectivity of sustainability indicators should be rooted in their ability to abridge complex issues and interrelationships, as well as their ability to quantify aspects of sustainability and condense vast volumes of information to advance a beneficial mechanism of feedback. Overall, the evidence suggests that the indicator-based frameworks make the sustainability assessment less complicated for researchers.

\section{Sustainability Rating Systems}

Another of the most frequently used methods in the collected sample of studies was sustainability rating systems. Studies applying the sustainability rating systems practice include Shen et al. (2011), Nguyen and Altan (2011), BREEAM (2012), Sharifi and Murayama (2013, 2015), Ameen et al. (2015), Yoon and Park (2015), Wangel et al. (2016), Elgert (2016), Diaz-Sarachaga (2016), Moroke et al. (2018), Cohen and Habron (2018), and Sparshott et al. (2018). These studies generally evaluate the strength and weakness of rating systems based on theoretical consideration, rationality, practicality and simplicity.

Most of the studies that apply sustainability rating systems often develop tools or software suitable for evaluating efficiencies in industries or programs pertinent to energy, renewable energy, and infrastructure. Popular computer programs utilised in sustainability rating practices include: the Building Research Establishment's Environmental Assessment Method (BREEAM) in Australia; Leadership in Energy and Environmental Design (LEED) that was developed by the Green Building Council in the US; the Comprehensive Assessment System for Building Environmental Efficiency (CASBEE ) in Japan; Green Star, by the Green Building Council of Australia; and HKBEAM, developed by Hong Kong Building Environmental Assessment Method Society. These computer programs are summarised in Nguyen and Altan (2011).

The review of the collected sample identified a series of rating systems for urban sustainability. One example was the Pearl Rating System for Estidama used in Abu Dhabi (see Ameen et al. 2015). The system was developed by the Abu Dhabi Urban Planning Council in 2010 as the first sustainability assessment framework in the 
eTropic 19.2 (2020) Special Issue: Sustainable Tropical Urbanism

Middle East and as a pathway toward 2030 Agenda. Ameen et al. (2015), and Reith and Orova (2015), provide further reviews of LEED-Neighbourhood Development, CASBEE-UD (Urban Development), Pearl Community Rating System (PCRS) and GSAS/QSAS.

Other detailed comparisons of BREEAM, LEED, and CASBEE for sustainability assessment of urban communities are offered in Berardi (2013), Yoon and Park (2015), and Lind et al. $(2017,2019)$. A complete review and the application of BREEAM is offered in BREEAM Communities Technical Manual (2012). Elgert (2016) reviewed the Sustainability Tools for Assessing and Rating system (STAR) program that is used in over 80 US communities and cities and argued that there is a trade-off between the feasibility and the credibility of the program. Similarly, Cohen and Habron (2018) reviewed the STAR program in US cities and found that the program does not adequately address the 2030 Agenda and the SDGs. Sparshott et al. (2018) took a similar approach to examine a sustainability assessment tool called Green Star Communities (Green-Star), an urban infill project in Canberra, Australia. The study found that because of the embedded weaknesses of the scoring system, the real outcomes of the project were not clear and there was a need for an alternative process.

Further analysis of data retrieved from rating systems is found in Sparshott et al. (2018), where a semi-structured interview was used to gain a deeper understanding of the Green-Star rating tool. While the urban sustainability rating systems have been well applied in many studies, there have been issues identified in the literature regarding the application of rating tools. For example, its flexibility, prescriptive nature, and focus on the internal environment (i.e. building) were criticised in Sparshott et al. (2018). Additionally, Sharifi and Murayama (2013) and Ameen et al. (2015) noted that most rating tools were not as practical they could be as they do not fully acknowledge the multidimensional nature of sustainable urban development. Some assessment tools have been expanded to accommodate aspects such as the built environment in cities, for example CASBEE-City used in Murakami et al. (2013). Furthermore, Cohen and Habron (2018) suggested that sustainable urbanisation strategies such as the New Urban Agenda (initiated after the Habitat III conference in Quito, Ecuador in October 2016) should be integrated into rating systems.

\section{Neighbourhood Development Indicators}

Several essential studies within the collected sample focused on neighbourhood indicators. These studies include Josza and Brown (2005), Shen et al. (2011), Lamorgese and Geneletti (2013), Sharifi and Murayama (2013, 2015), Ameen et al. (2015), Yoon and Park (2015), Angel and Blei (2016), Wangel et al. (2016), Lind et al. (2017), Stojanovski $(2017,2019)$, Lind et al. (2019), Moroke et al. (2018), Sparshott 
eTropic 19.2 (2020) Special Issue: Sustainable Tropical Urbanism

et al. (2018), Zhai et al. (2019), and Wilkerson et al. (2018). These studies explored neighbourhood settings, pre-conditions, and dynamics that may revitalise local development initiatives. Researchers in the fields of urban economics and urban planning have attempted to design frameworks for a better understanding of sustainable neighbourhood development. These neighbourhood indicators help retain and enhance neighbourhood special characters and qualities. As stated in Michael et al. (2014) and Lind et al. (2019), the process of developing these frameworks included collaborative rendezvous between researchers, policymakers and planners with a focus on target setting and performance review processes. Selected studies in this scoping review reveal that multiple indicators have been used differently in different locations to accommodate a variety of neighbourhood needs, for instance: Josza and Brown (2005), Shen et al. (2011) and Lamorgese and Geneletti (2013).

A handful of the selected studies such as Ciegis et al. (2009) focused on the use of local/neighbourhood indicators, while some others such as Shen et al. (2011) developed a review framework using 71 sustainability and climate change-related questions to create an assessment tool that was subsequently used in auditing sustainability reports of 15 major Italian cities. Throughout the process, they identified danger zones, tipping points and scenarios under which environmental, economic and social destruction deemed irreversible. Other studies such as Michael et al. (2014) provided a review around ecological, social, and economic dimensions of urban sustainability indicators. They applied these indicators and their relevant data in the contexts of China, Malaysia and Taiwan. The study used a framework for categorising process-content integration and outcomes for each selected country and found that while each country is dealing with their different challenges, they have attempted to integrate some aspects of urban sustainability into their policies. Michael et al. recommended further integration of urban indicators into policies. Similarly, Huang et al. (2015) used the same approach as Michael et al. (2014) to develop urban sustainability indicators to gauge the state and progress of urban sustainability.

More recent studies such as Moroke et al. (2018) and Verovsek et al. (2016) developed neighbourhood sustainability frameworks to quantify urban system sustainability and to measure the quality of life in neighbourhoods and cities. They identified several challenges in developing sustainable urban indicators without a detailed assessment of the characteristics of selected neighbourhoods. Wangel et al. (2016) viewed neighbourhood development indicators as guidance for urban development projects. They provided an in-depth analysis of two systems: BREEAM Communities (BREEAM-C) and LEED-Neighborhood Development, by focusing on distinguishing features of the systems concerning sustainable development. Wilkerson et al. (2018) reviewed studies with a focus on neighbourhoods with socio-economic disadvantages that are further challenged by social inequality, lack of attention to 
eTropic 19.2 (2020) Special Issue: Sustainable Tropical Urbanism

public and green spaces, and inadequate land management. The study found that socio-economic characteristics of neighbourhoods influence the demand and supply for urban ecosystem services, and suggested that only urban planning that incorporates these factors into the delivery and design of green spaces would be successful in achieving sustainable neighbourhood development.

Additionally, Stojanovski $(2017,2019)$ developed sustainable mobility indicators on urban mobility and proposed a methodology to forecast mobility choices on a neighbourhood scale. McGranahan et al. (2003) looked at the controversies around the connections between sustainability and cities and proposed criteria that should be included in urban sustainability frameworks. They discussed the importance of a city's ability to contribute to not only sustainability goals within their boundaries, but also the global goals. Mischen et al. (2019) provided a critique of sustainability assessment systems at the different levels of neighbourhood, municipal, national and global, and recommended the application of the Community Sustainability Assessment System (CSAS).

In summary, these studies concluded that most of the sustainability rating tools come with several weaknesses because of their bias in selecting feature indicators over the actual indicators (Wangel et al., 2016). They also concluded that there is no one single set of indicators that would be suitable equally for all neighbourhoods and cities of different sizes and characteristics (Shen et al., 2011).

\section{Multi-Criteria Decision Analysis (MCDA)}

Another popular approach in the collected sample was the application of Multi-Criteria Decision Making (MCDM) or Multi-Criteria Decision Analysis (MCDA). Studies that used this method included: Mosadeghi et al. (2009), Pavan and Todeschini (2009), Schetke et al. (2012), Egilmez (2015), Kropp and Lein (2013), Saarikoski et al. (2016) and Awasthi et al. (2018).

MCDM is primarily the application of advanced analytical techniques used to make better decisions. Multi-Criteria Decision Analysis, or MCDA, is an all-purpose framework that specifically evaluates incompatible objectives or dissimilar information in decision making (Saarikoski et al. 2016). One of the major strengths of MCDA is its ability to assess multiple conflicting criteria simultaneously. The method is also concerned with the choice of decisions that involve identifying the best alternative from several potential candidates using systematic analysis subjected to pre-determined selection criteria or attributes that may be either concrete or vague (Pavan \& Todeschini, 2009). Mosadeghi et al. (2009) support the use of MCDA in planning, as it provides a fair combination of contemporary planning objectives. Mosedeghi et al. 
eTropic 19.2 (2020) Special Issue: Sustainable Tropical Urbanism

(2009) also argue that MCDA is useful for autonomous identification and ranking of the most suitable planning decisions.

The application of MCDA in sustainability studies is on the rise as it provides a performance evaluation tool for alternative policy options against multidimensional criteria concerned with social, environmental and economic sustainability aspects. The process of decision-making will ultimately involve human judgement. An example is Schetke et al. (2012). They developed a multi-criteria decision framework to assess the sustainability and resource efficiency of green-fields vs infill development in Essen, Germany. The method was ultimately called a Multi-Criteria Assessment-Decision Support Criteria (MCA-DSS) network that was developed by utilising a stakeholderdriven approach. A large group of city planners, university researchers and city councils participated in the method's development process, which was subjected to the selection of a set of indicators. Subsequently, numerous potential indicators were discussed and the most suitable indicators selected following a participatory approach. Other indicators such as design and usability in the decision-making process were also considered; this enabled the authors to identify housing development strategies that aligned closely with the city and regional sustainability goals.

The MCDA was also applied in a spatial domain in the work of Kropp and Lein (2013) who examined the sustainability assessment challenges within specific urban settings. The method was initially developed by conducting an effective assessment of a problem, which was then followed by data collection, pre-processing, identifying the influences (e.g. social interactions, community connectivity, historic sites) and constraints (e.g. prime farmland, parkland, floodplain avoidance), model development and finally evaluation of the model using scenario analysis. The study found that scenarios were vital in managing semantic uncertainties surrounding the concept of sustainability.

To evaluate environmental sustainability performance, Egilmez et al. (2015) applied a four-step tiered MCDA in a metropolitan region. Throughout these four steps, the authors assessed 16 sustainability indicators and contacted experts for their evaluation of these indicators across 27 metropoles. They then developed a Fuzzy Decision-Making model and quantified sustainability performance scores. They found that this method was particularly useful when handling data that have both positive and negative impacts on sustainability outcomes with different scales of measurement. Mitropoulos and Prevedouros (2016) compared two MCDM methods (i.e. the Weighted Sum Method, and the Fuzzy Logic method) to rank sustainability performance of urban vehicles. They found that systematic differences between methods yielded different outcomes. They argue that the weighted sum method, while it is the most commonly used method for decision making, proves to be too sensitive 
eTropic 19.2 (2020) Special Issue: Sustainable Tropical Urbanism

to extreme data values. In contrast, the fuzzy logic method proved to be more flexible, more stable and capable of handling inter-relationships between inter-dimensional indicators. The fuzzy logic method was also found to preferable due to its ability to combine and manage inaccurate and unclear information.

In summary, MCDA was supported by authors for several reasons including:

- its technical capability of assessing infill planning strategies vs. green-field development (Schetke et al. 2012)

- its practicality and strength in land suitability analysis when deciding for future cities (Mosadeghi, 2009)

- its applicability in enhancing future strategic planning for land monitoring and control alongside sustainability measures (Schetke et al. 2012)

- its ability to explore plausible alternatives and to offer insight regarding the spatial pattern of sustainable urban development under differing constraints (Kropp \& Lein, 2013).

\section{Urban Metabolism, Principle-Based Framework, and Impact Assessment}

Other popular methods applied in the selected studies were urban metabolism, principle-based framework, and impact assessment. Notable studies in the sample include Browne et al. (2005), Ciegis et al. (2009), Gonzalez et al. (2011), Pincetl et al. (2012), Mortberg et al. (2013), Lamorgese and Geneletti (2013), Huang et al. (2015), Zanella et al. (2015), Riffat et al. (2016), Cohen (2017), Venkatesh et al. (2017), Ulgiati and Zucaro (2019), and Cepeliauskaite and Stasiskiene (2020).

As stated in Pincetl et al. (2012), urban metabolism methods analyse the flow of materials and energy within urban areas that allow researchers to use a metabolism framework to study the connections between environmental and social systems in a specific region. Browne et al. (2005) were one of the early researchers that applied urban metabolism method in measuring resource efficiency in a town setting. Later Gonzalez et al. (2011) integrated urban metabolism into a decision support system and applied the assessment framework to five cities. The study found that planning priorities significantly influence the extent and scope of sustainability indicators. Huang et al. (2015) analysed the relationship between urban metabolism and land-use practices. Venkatesh et al. (2017) compared two metabolism-based approaches for urban water services and found both approaches are useful in exploring the influence of external drivers. 
eTropic 19.2 (2020) Special Issue: Sustainable Tropical Urbanism

Ciegis et al. (2009) and Cohen (2017) suggested that principle-based frameworks should be developed primarily based on sustainable development goals combined with sustainability indicators. Ulgiati \& Zucaro (2019) argued that studying dimensions of urban metabolism such as the well-being of the citizen, and the city's liveability should be centre-stage when developing principles of sustainability solutions. Alternatively, these frameworks could help establish a stand-alone assessment framework similar to the Strategic Environmental Assessment Framework used in Lamorgese and Geneletti (2013). Their framework was based on seven principles including socio-ecological system integrity, intra-generational and inter-generational equity, cost-effectiveness, efficiency and resource maintenance and immediate and long-term integration issues.

Finally, the impact assessment approach is based on the application of assessment tools such as the Land-Use Evolution and Impact Assessment (LEAM) applied in Mortberg et al. (2013) to assess the ecological implication of land use. In a recent study by Cepeliauskaite and Stasiskiene (2020), the principles-based approach was conceptualised to look at sustainable urban ecosystems. The study discussed how different principles of different constructs could interact with each other in order to build a foundation to extract a set of broad principles of sustainable urban ecosystems.

\section{Climate Classifications and Geographical Locations Matter}

The geographical scope of the reviewed studies is presented as a bar chart, while the overall percentage of methods used in these studies is presented as a pie chart in Figure 6. Geographically, the methods applied slightly differ from the prevalent techniques applied in the literature. The comparison between the summary of methods in Figure 4 with the pie chart in Figure 6 reveals that while indicator or index-oriented frameworks maintain a dominant approach in the two figures, the global share of impact assessment and urban carrying capacity methods in urban studies is $16 \%$ and $13 \%$, respectively. The geographical application of the urban metabolism method increased to $8 \%$ compared to the $6 \%$ application in urban sustainability literature.

The sustainability rating system declined from $19 \%$ to $13 \%$ when the method is analysed from a geographical perspective. Other methods with a lower overall geographic application are multi-criteria decision analysis at $5 \%$, spatial analysis and urban form at $3 \%$, and eco-efficiency assessment at $2 \%$. There is also an indication of a multi-polar geographical tendency among selected studies focused on the temperate zone. From a country-level perspective, studies with a focus on China dominate in the diversity of methods used with six methods applied in twelve studies. In the USA, eleven studies used three different methods. Belgium and Sweden had 
four different methods used in five studies. The next set of countries with three different methods includes Italy, Brazil, Australia, Taiwan, Spain, Poland and Japan. Across Figure 6, indicator or index-oriented frameworks are the most urban sustainability oriented methods applied across several geographical locations, and this includes the three out of five tropical countries of Singapore, Malaysia, and Taiwan.

Figure 6 Geographical distribution of the methods applied

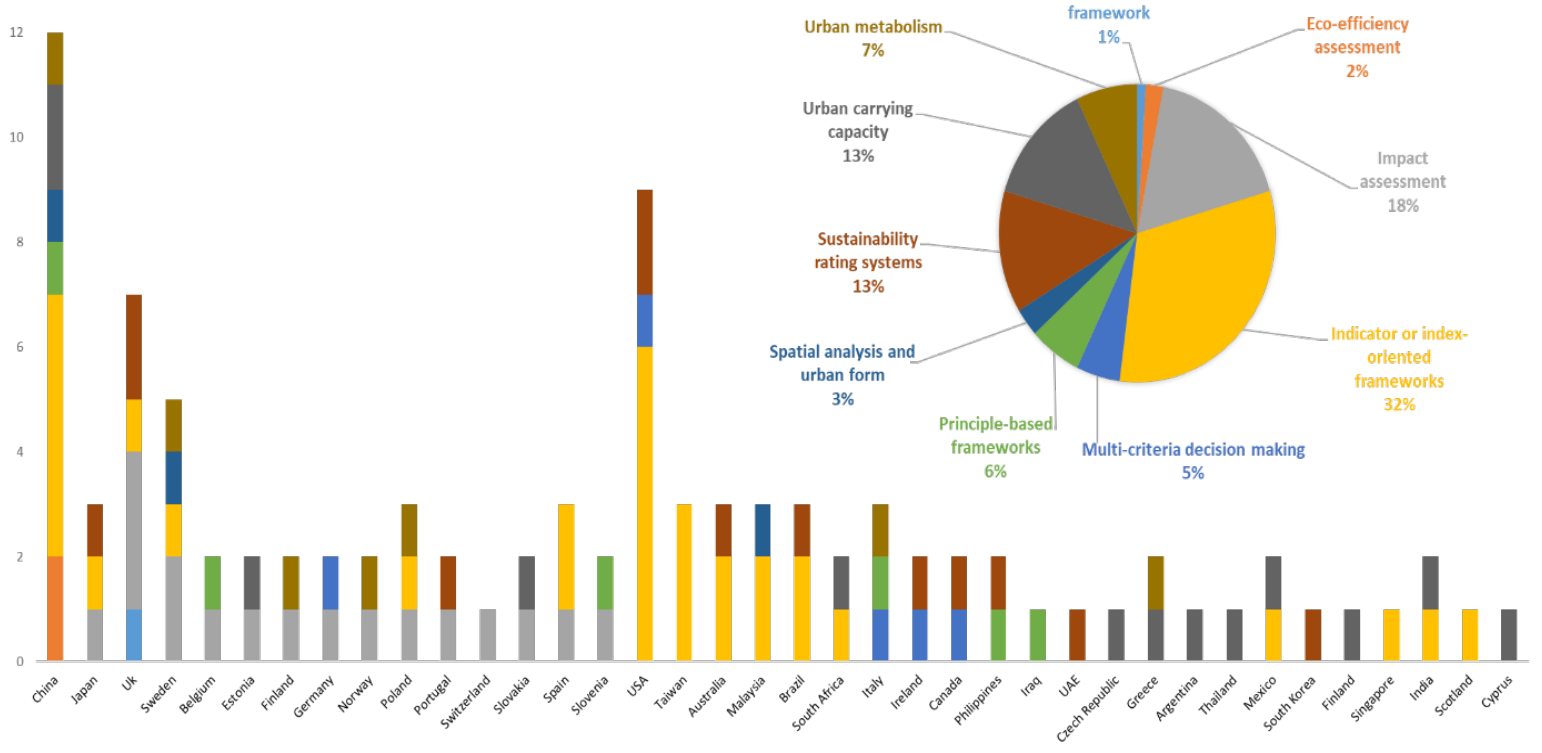

In China, research has mainly focused on addressing environmental issues. For example, van Dijk and Mingshun (2005) used four medium-sized cities in China as case studies to measure urban sustainability through the application of the urban sustainability index. Their study found that the economic performance in these cities affects urban developments, which can be crucial in achieving urban sustainability. The study also found that factors such as fast economic growth and rapid urbanisation have resulted in environmental degradation in Chinese cities, and acted as impediments in achieving urban sustainability.

The research suggests that immediate attention should be paid to environmental protection and management schemes. Lin et al. (2010) assessed urban eco-efficiency in the city of Xiamen in China and found that eco-efficiency, resource efficiency and environmental efficiency declined 0.155-, 0.157- and 0.153-times from 2000 to 2006. Yin et al. (2014) identified cities in the southwest and northwest of China as the most inefficient in the country and largely underdeveloped. Sun et al. (2010) noted that Mainland China had an uneven distribution of urban sustainability. He et al. (2011) considered the undesired outcomes of uncontrollable urbanisation and recommended that ecological planning principles be integrated into urban planning principles. They 
eTropic 19.2 (2020) Special Issue: Sustainable Tropical Urbanism

also suggested that to avoid inconsistencies when approaching sustainability goals, key stakeholders such as administrative, environmental, and urban authorities should unify and collaboratively develop a better understanding of urban sustainability.

Further, Ding et al. (2015) suggested that for a more regenerative development path, there is a need for the revitalisation of urban systems, urban planning, and consultation with local communities to increase awareness about issues pertinent to sustainable development. In capital cities such as Beijing in China, Huang et al. (2015) concluded that the city should focus on the principles and development of the circular economy ${ }^{2}$ and improve land-use practices to achieve smart and effective economic development. Other studies recommended using urban carrying capacity as a benchmarking method that pays close attention to a set of urban indicators over time.

Overall, these studies suggested that urban indicators need to be well-maintained and accurately monitored over dynamic time frames. The urban carrying capacity seems to be of particular value when studying over-developed and over-concentrated cities. The method can benchmark decentralisation policies, the efficiency of investment and resource allocation, and the efficiency of land-use plans with an aim to transforming consumptive lifestyles to environment-friendly lifestyles (Wei et al., 2015; Zhai et al., 2019).

In the city of Worcester in Massachusetts, USA, Kropp and Lein (2013) noted that sustainable development in the city focused on the centre of the municipality and then extended eastwards along the transport route. The study indicated that social interactions were vital to expand sustainable areas. Cohen and Habron (2018) examined the outcome of an urban planning process called the New Urban Agenda for Asheville in the US state of North Carolina. The New Urban Agenda seemed compatible with the existing Asheville Comprehensive Plan, particularly when handling environmental and social dimensions. However, the Cohen and Habron study found that the New Urban Agenda considers the governance dimension at the city-level, which is problematic as it fails to resolve conflicts arising from the confrontation between decentralised decision making processes and top-down federal powers. The study recommended integrating the principles of the New Urban Agenda into existing sustainability frameworks focusing particularly on equality and reconciling governance approaches into sustainability plans.

In Australia, Shen et al. (2011) compared nine different sustainable urbanisation practices in the city of Melbourne using urban sustainability indicators. They found the city does not perform well in dealing with social and governance dimensions such as

\footnotetext{
${ }^{2}$ On Circular Econony design in the context of two tropical cities, see Fleischmann, (2018).
} 
eTropic 19.2 (2020) Special Issue: Sustainable Tropical Urbanism

health, safety, fire and emergency response, poverty, natural hazards, adequate housing, access to credit and land, recreation, transport, etc. The study suggested that while not all sets of indicators are suitable for all communities, some degree of standardisation in the process of the development of indicator sets is required. Sparshott et al. (2018) examine the adaptation of sustainability indicators in urban areas and analyse the Green-STAR rating scheme that was adopted under the City to Lake Project in Canberra, Australia. They found that the application of the assessment tool was beneficial and provided a useful guide for the implementation of green building practices and determining advancements towards sustainability goals. However, Sparshott et al. (2018) found several shortcomings including cost implications and the complexity that comes with the application of sustainability rating tools due to challenges and barriers of implementation; particularly at the neighbourhood level, where different degrees of social interaction, environmental and locational mechanisms are significant.

Notably, the selected studies do not demonstrate evidence of the application of any climate-based urban planning. This highlights a precarious aspect regarding the studies, as climatic-classifications and geographical locations influence the characteristics of urban systems. The assessment of the selected studies indicates that while there is a widespread acknowledgment of rapid deterioration of resources available to human-centred systems, none of the studies paid attention to climatespecific characteristics of the urban systems, which is particularly necessary when dealing with the objectivity of sustainability indicators. As tropical cities are swiftly expanding due to the growth of tropical economies and accelerating demographics, effective integration of regional climate information into urban planning methodologies has never been more relevant.

In summary, while there are a large number of modelling techniques for climate change adaptation to aid planners, there is still a strong need for co-planning and codesign processes to develop impact-modelling methodologies that are climate effective and environmentally just. Furthermore, there might be a lack of quantitative modelling skills among local authorities to develop a comprehensive multidimensionalmethod (as also indicated in Sang \& Ode Sang, 2015). This observation calls for collaborative processes between practitioners and researchers. Lastly, to avoid multipolar tendencies in repeatedly applying the existing methods, there is a growing need for comprehensive and contemporary urban development models with better demonstrated predictive capabilities. 
eTropic 19.2 (2020) Special Issue: Sustainable Tropical Urbanism

\section{Conclusion}

Through multidisciplinary lenses, this scoping review attempted to improve the conceptual understanding of methods used in sustainable urban development studies. In addition, this paper suggests the importance of incorporating geographic characteristics, regional climate information, and the neighbourhood's socio-economic factors when developing sustainable urban frameworks.

As discussed in the methodology, 195 articles were collected using specific search criteria. After de-replication and a second round of screening, 98 research works met the eligibility criteria based on relevance in titles and abstracts. The study then proceeded to acquire full-text articles. Five articles were unobtainable so were removed from the review. Ten others were removed on the third screening by reviewing abstracts and using specific search terms. Upon finalisation, 83 full-text articles were included in the final evaluation.

The scoping review identified the ten most commonly used methodological approaches: indicator-index framework, principle-based framework, multi-criteria decision analysis, sustainability rating systems, principle-based frameworks, urban metabolism, impact assessment, urban carrying capacity, eco-efficiency framework, and asset-based framework. Most of these methods have gained visibility in recent years. The review revealed how each of these methodological approaches come with strengths and weaknesses, affecting the selection of parameters, assessment, design processes, and the interpretation of results. The findings of the review indicates that there is a need for a more comprehensive methodological innovation that covers all factors and essential dimensions pertinent to urban sustainability.

Finally, this review reveals that some urban sustainability frameworks do not perform well when dealing with the objectivity of sustainability indicators including, but not limited to: social inequality, governance, impoverished neighbourhoods, or natural hazards. This review reiterates that climatic-classifications and geographical locations influence the characteristics of urban systems, suggesting the importance of incorporating regional climate information in urban planning methodologies. The review also finds that understanding the characteristics and dynamics of different neighbourhoods would lead to the development of initiatives that could be scaled up to city level and beyond. Finally, this review indicates the possibility of a multi-polar geographical tendency in the literature that is mainly focused on the temperate zone. This final observation calls for more comprehensive research with a focus on tropical cities, with a focus on climate, while also accounting for rapid economic growth and accelerating demographics. 
eTropic 19.2 (2020) Special Issue: Sustainable Tropical Urbanism

\section{References}

Abu Dhabi Urban Planning Council (2010). The Pearl Rating System for Estidama: Community Rating System. Abu Dhabi.

Arksey, H. O'Malley, L. (2005). Scoping studies: towards a methodological framework. International Journal of Social Research Methodology, 8 (1), 2005. https://doi.org/10.1080/1364557032000119616

Ameen, R. F. M., Mourshed, M., \& Li, H. (2015). A critical review of environmental assessment tools for sustainable urban design. Environmental Impact Assessment Review, 55, 110-125. https://doi.org/10.1016/j.eiar.2015.07.006

Angel, S., \& Blei, A. M. (2016). The productivity of American cities: How densification, relocation, and greater mobility sustain the productive advantage of larger US metropolitan labour markets, Cities, 51, 36-51. https://doi.org/10.1016/j.cities.2015.11.030

Atkisson, A., \& Hatcher, R. L. (2001). The compass index of sustainability: Prototype for a comprehensive sustainability information system. Journal of Environmental Assessment Policy and Management, 3(04), 509-532. https://doi.org/10.1142/S1464333201000820

Awasthi, A., Omrani, H., \& Gerber, P. (2018). Investigating ideal solution based multi-criteria decision-making techniques for sustainability evaluation of urban mobility projects. Journal of Policy and Practice, 116, October 2018, 247-259. https://doi.org/10.1016/j.tra.2018.06.007

Balchin, P. N., Kieve, J. L., \& Bull, G. H. (1988). Spatial Structure and Urban Growth. Editor: I.H. Seeley, In Urban Land Economics and Public Policy (pp. 55-86). London: Macmillan Education, UK.

Berardi, U. (2013). Sustainability assessment of urban communities through rating systems. Journal of Environment, development and sustainability, 15(6), 1573-1591. https://doi.org/10.1007/s10668-013-9462-0

Braulio-Gonzalo, M., Bovea, M. D., \& Ruá, M. J. (2015). Sustainability on the urban scale: Proposal of a structure of indicators for the Spanish context. Journal of Environmental Impact Assessment Review, 53, 16-30. https://doi.org/10.1016/j.eiar.2015.03.002

BREAM Communities Technical Manual (2012). BREEAM Communities Technical Manual. SD202 - Issue:1.1 - Issue Date:07/03/2016 BREEAM Communities. Watford, UK

Browne, D., O'Regan, B., \& Moles, R. (2005). A comparative analysis of the application of sustainability metric tools using Tipperary Town, Ireland, as a case study. Journal of Management of Environmental Quality, 16 (1), 37-56. https://doi.org/10.1108/14777830510574335

Bockstaller, C., Girardin, P. (2003). How to validate environmental indicators. Journal of Agricultural Systems. 76 (2), 639-653. https://doi.org/10.1016/S0308-521X(02)00053$\underline{7}$

Cepeliauskaite, G., \& Stasiskiene, Z. (2020). The Framework of the Principles of Sustainable Urban Ecosystems Development and Functioning. Journal of Sustainability 12 (720), 1-15 https://doi.org/10.3390/su12020720

Chang, D.L., Sabatini-Marques, J., da Costa, E.M. et al. (2018). Knowledge-based, smart and sustainable cities: a provocation for a conceptual framework. Journal of Open Innovation: Technology, Market, and Complexity, 4 (5).

https://doi.org/10.1186/s40852-018-0087-2 
eTropic 19.2 (2020) Special Issue: Sustainable Tropical Urbanism

Ciegis, R., Ramanauskiene, J., \& Startiene, G. (2009). Theoretical reasoning of the use of indicators and indices for sustainable development assessment. Journal of Engineering Economics, 63(4).

Cohen, M. (2017). A Systematic Review of Urban Sustainability Assessment Literature. Sustainability, 2017, 9, 2048. https://doi.org/10.3390/su9112048

Cohen, M., \& Habron, G. (2018). How Does the New Urban Agenda Align with Comprehensive Planning in US Cities? A Case Study of Asheville, North Carolina. Sustainability, 10(12), 4590. https://doi.org/10.3390/su10124590

Davidson, K. M., Kellett, J., Wilson, L., \& Pullen, S. (2012). Assessing urban sustainability from a social democratic perspective: a thematic approach. Local Environment, 17(1), 57-73. https://doi.org/10.1080/13549839.2011.631990

Diaz-Sarachaga, J.M. (2016).The Role of Sustainable Infrastructure Rating Systems in Urban Development. Conference: International Congress of Civil Engineering, Madrid, Spain, retrieved from https://www.researchgate.net/publication/296647048 The Role of Sustainable Infr astructure Rating Systems in Urban Development

Ding, X., Zhong, W., Shearmur, R. G., Zhang, X., \& Huisingh, D. (2015). An inclusive model for assessing the sustainability of cities in developing countries-Trinity of Cities' Sustainability from Spatial, Logical and Time Dimensions (TCS-SLTD). Journal of Cleaner Production, 109, 62-75. https://doi.org/10.1016/j.jclepro.2015.06.140

Egilmez, G., Gumus, S., \& Kucukvar, M. (2015). Environmental sustainability benchmarking of the US and Canada metropoles: An expert judgment-based multi-criteria decisionmaking approach. Cities, 42, 31-41. https://doi.org/10.1016/j.cities.2014.08.006

Elgert, L. (2016). The double edge of cutting edge: Explaining the adoption and nonadoption of the STAR rating system and insights for sustainability indicators. Ecological Indicators, 67, 556-564. https://doi.org/10.1016/j.ecolind.2016.02.051

Eyles, J. (2007). Urban assets and urban sustainability: challenges, design and management. WIT Transactions on Ecology and the Environment. Vol 102, WIT Press. https://doi:10.2495/SDP070131

Emilsson, T., Sang, A.O. (2017). Impacts of Climate Change on Urban Areas and NatureBased Solutions for Adaptation. In: Kabisch N., Korn H., Stadler J., Bonn A. (eds) Nature-Based Solutions to Climate Change Adaptation in Urban Areas. Theory and Practice of Urban Sustainability Transitions (pp 15-27). Springer, Cham

Fitria, R., Kim, D., Baik, J., Choi, M. (2019). Impact of Biophysical Mechanisms on Urban Heat Island Associated with Climate Variation and Urban Morphology. Sci Rep, 9, 19503. https://doi.org/10.1038/s41598-019-55847-8

Fleischmann, K. (2018). Design Evolution and Innovation for Tropical Liveable Cities: Towards A Circular Economy. eTropic: electronic journal of studies in the tropics, 17 (1), 60-73. http://dx.doi.org/10.25120/etropic.17.1.2018.3642

Gonzalez, A., Donnelly, A., Jones, M., Klostermann, J., Groot, A., \& Breil, M. (2011). Community of practice approach to developing urban sustainability indicators. Journal of Environmental Assessment Policy and Management,13(04), 591-617. https://doi.org/10.1142/S1464333211004024

Hardi, P., Zdan, T., (1997), Principles in Practice. Assessing Sustainable Development IISDInternational Institute for Sustainable Development, Winnipeg.

Harding, S., Bird, G., Losos, E., Aderolili, R., \& Hotez, P. (2016). International Day of the Tropics: Towards a better global future. eTropic: electronic journal of studies in the tropics 15 (2), 5-12. https://doi.org/10.25120/etropic.15.2.2016.3538

He, J., Bao, C. K., Shu, T. F., Yun, X. X., Jiang, D., \& Brwon, L. (2011). Framework for integration of urban planning, strategic environmental assessment and ecological planning for urban sustainability within the context of China. Environmental Impact Assessment Review, 31(6), 549-560. https://doi.org/10.1016/j.eiar.2010.09.002 
eTropic 19.2 (2020) Special Issue: Sustainable Tropical Urbanism

Hockey, J. (2014). Keynote Address, Future of the Tropical Economies Conference, Cairns. Australian Government. The Treasury. http://jbh.ministers.treasury.gov.au/speech/017-2014/

Huang, L., Wu, J., \& Yan, L. (2015). Defining and measuring urban sustainability: A review of indicators. Landscape Ecology, 30(7), 1175-1193. https://doi.org/10.1007/s10980015-0208-2

Josza, A., Brown, D. (2005). Neighbourhood Sustainability Indicators Report on a Best Practice Workshop - Report. School of Urban Planning, McGill University and the Urban Ecology Center/SodemC, Montreal.

Kropp, W. W., \& Lein, J. K. (2013). Scenario analysis for urban sustainability assessment: A spatial multi-criteria decision-analysis approach. Environmental Practice, 15(2), 133146. https://doi.org/10.1017/S1466046613000045

Lamorgese, L., \& Geneletti, D. (2013). Sustainability principles in strategic environmental assessment: A framework for analysis and examples from Italian urban planning. Environmental Impact Assessment Review, 42, 116-126. https://doi.org/10.1016/..eiar.2012.12.004

Lin, J., Li, Y., Wang, W., Cui, S., \& Wei, X. (2010). An eco-efficiency-based urban sustainability assessment method and its application. International Journal of Sustainable Development \& World Ecology, 17(4), 356-361. https://doi.org/10.1080/13504509.2010.493070

Lind, J., Malmqvist, T., \& Wangel, J. (2017). Citylab Action: Guiding Sustainable Urban Development. In World Sustainable Built Environment Conference, Hong Kong.

Lind, J., Malmqvist, T., \& Wangel, J. (2019). Key Considerations When Designing Certification Systems for Urban Sustainability and Implications for The Swedish PostConstruction System Citylab. Sustainability, 11(9), 2673. https://doi.org/10.3390/su11092673

Lutzkendorf, T., \& Balouktsi, M. (2017). Assessing sustainable urban development: Typology of indicators and sources of information. Procedia Environmental Sciences, 38, 546553. https://doi.org/10.1016/j.proenv.2017.03.122

Masnavi, M. R. (2007). Measuring urban sustainability: Developing a conceptual framework for bridging the gap between theoretical levels and operational levels. International Journal of Environmental Research, 1(2), 188-197.

Mathie, A., Cunningham, G., (2003). From Clients to Citizens: Asset-Based Community Development as a Strategy for Community-Driven Development. Journal of Development in Practice, 13 (5), 474-486. https://doi.org/10.1080/0961452032000125857

McGranahan, G., \& Satterthwaite, D. (2003). Urban centres: an assessment of sustainability. Annual Review of Environment and Resources, 28(1), 243-274. https://doi.org/10.1146/annurev.energy.28.050302.105541

McLaren, V. W., (1996). Urban Sustainability reporting. Journal of the American Planning Association, 62 (2), 184-203. https://doi.org/10.1080/01944369608975684

Michael, F. L., Noor, Z. Z., \& Figueroa, M. J. (2014). Review of urban sustainability indicators assessment-case study between Asian countries. Habitat International, 44, 491-500. https://doi.org/10.1016/j.habitatint.2014.09.006

Mischen, P. A., Homsy, G. C., Lipo, C. P., Holahan, R., Imbruce, V., Pape, A.,\& Reina, M. (2019). A Foundation for Measuring Community Sustainability. Sustainability, 11(7), 1903. https://doi.org/10.3390/su11071903

Mitropoulos, L. K., \& Prevedouros, P. D. (2016). Urban transportation vehicle sustainability assessment with a comparative study of weighted sum and fuzzy methods. Journal of Urban Planning and Development, 142(4), 04016013. https://doi.org/10.1061/(ASCE)UP.1943-5444.0000336 
eTropic 19.2 (2020) Special Issue: Sustainable Tropical Urbanism

Mosadeghi, R. Tomlinson, R., Mirfenderesk, H., Warnken, J. (2009). Journal of Coastal Research, Coastal Management Issues in Queensland and Application of the MultiCriteria Decision Making Techniques, Special Issue No. 56. Proceedings of the 10th International Coastal Symposium ICS 2009, Vol. II, pp. 1252-1256

Mori, K., \& Christodoulou, A. (2012). Review of sustainability indices and indicators: Towards a new City Sustainability Index (CSI). Environmental Impact Assessment Review, 32(1), 94-106. https://doi.org/10.1016/j.eiar.2011.06.001

Mori, K., \& Yamashita, T. (2015). Methodological framework of sustainability assessment in City Sustainability Index (CSI): A concept of constraint and maximisation indicators. Habitat International, 45, 10-14. https://doi.org/10.1016/j.habitatint.2014.06.013

Moroke, T., Schoeman, C., \& Schoeman, I. (2018). Integrative and modelling approach to sustainability modes of living and neighbourhood development. WIT Transactions on the Built Environment, 179, 145-157. https://DOI:10.2495/UG180141

Mortberg, U., Haas, J., Zetterberg, A., Franklin, J. P., Jonsson, D., \& Deal, B. (2013). Urban ecosystems and sustainable urban development-analysing and assessing interacting systems in the Stockholm region. Urban Ecosystems, 16(4), 763-782. https://doi.org/10.1007/s11252-012-0270-3

Munier, N. (2011). Methodology to select a set of urban sustainability indicators to measure the state of the city, and performance assessment. Ecological Indicators, 11(5), 1020-1026. https://doi.org/10.1016/..ecolind.2011.01.006

Murakami, S., Asami, M. Y., Ikaga, T., Ishida, H., Inoue, K., \& Iwamura, K. (2013). Environmental Performance Assessment Tool for Municipalities: Overview of CASBEE for Cities. Comprehensive Assessment System for Built Environment Efficiency: Tokyo, Japan, 1-3.

Niemeijer, D., \& de Groot, R.S. (2008). A conceptual framework for selecting environmental indicator sets. Ecological Indicators, 8(1), 14-25. https://doi.org/10.1016/j.ecolind.2006.11.012

Nguyen, B. K., \& Altan, H. (2011). Comparative review of five sustainable rating systems. Procedia Engineering, 21, 376-386. https://doi.org/10.1016/j.proeng.2011.11.2029

Olalla-Tárraga, M. Á. (2006). A conceptual framework to assess sustainability in urban ecological systems. The International Journal of Sustainable Development and World Ecology, 13(1), 1-15. https://doi.org/10.1080/13504500609469657

Oppermann, E., Brearley, M., Law, L., Smith, J.A., Clough, A., Zander, K. (2017). Heat, health, and humidity in Australia's monsoon tropics: a critical review of the problematisation of 'heat' in a changing climate. In M. Hulme (Ed.), WIREs Climate Change, Wiley Periodicals 8:e468. https://doi.org/10.1002/wcc.468

Pavan, M., \& Todeschini, R. (2009). Multicriteria Decision-Making Methods. In S. D. Brown, R. Tauler, \& B. Walczak (Eds.), Comprehensive Chemometrics (pp. 591-629). Elsevier.

Pincetl, S., Bunje, P., \& Holmes, T. (2012). An expanded urban metabolism method: Toward a systems approach for assessing urban energy processes and causes. Landscape and Urban Planning, 107 (3), 193-202 https://doi.org/10.1016/j.landurbplan.2012.06.006

Porio, E. (2015). Sustainable development goals and quality of life targets: Insights from Metro Manila. Current Sociology, 63(2), 244-260. https://doi.org/10.1177/0011392114556586

Reith, A., \& Orova, M. (2015). Do green neighbourhood ratings cover sustainability? Ecological Indicators, 48, 660-672. https://doi.org/10.1016/j.ecolind.2014.09.005

Ries, M., Trotz, M., \& Vairavamoorthy, K. (2016). Fit-for-Purpose sustainability index: a simplified approach for US water utility sustainability assessment. Water Practice and Technology, 11(1), 35-47. https://doi.org/10.2166/wpt.2016.009 
eTropic 19.2 (2020) Special Issue: Sustainable Tropical Urbanism

Riffat, S., Powell, R., \& Aydin, D. (2016). Future cities and environmental sustainability. Journal of Future Cities and Environment, 2(1), https://doi.org/10.1186/s40984-016$\underline{0014-2}$

Saarikoski, H., Barton, D. N., Mustajoki, J., Keune, H., Gomez-Baggethun, E., \& Langemeyer, J. (2016). Multi-criteria decision analysis (MCDA) in ecosystem service valuation. In M. Potschin \& K. Jax (Eds), OpenNESS ecosystem services reference book (pp. 1-6).

Sang N, Ode Sang A. (2015). A review on the state of the art in scenario modelling for environmental management, Report 6695. Swedish Environmental Agency, Stockholm.

Schetke, S., Haase, D., \& Kötter, T. (2012). Towards sustainable settlement growth: A new multi-criteria assessment for implementing environmental targets into strategic urban planning. Environmental Impact Assessment Review, 32(1), 195-210. https://doi.org/10.1016/j.eiar.2011.08.008

Scipioni, A., Mazzi, A., Zuliani, F., \& Mason, M. (2008). The ISO 14031 standard to guide the urban sustainability measurement process: an Italian experience. Journal of Cleaner Production, 16(12), 1247-1257. https://doi.org/10.1016/j.jclepro.2007.06.013

Sharifi, A., \& Murayama, A. (2013). A critical review of seven selected neighbourhood sustainability assessment tools. Environmental Impact Assessment Review, 38, 7387. https://doi.org/10.1016/i.eiar.2012.06.006

Sharifi, A., \& Murayama, A. (2015). Viability of using global standards for neighbourhood sustainability assessment: insights from a comparative case study. Journal of Environmental Planning and Management, 58(1), 1-23. https://doi.org/10.1080/09640568.2013.866077

Shen, L. Y., Ochoa, J. J., Shah, M. N., \& Zhang, X. (2011). The application of urban sustainability indicators-A comparison between various practices. Habitat International, 35(1), 17-29. https://doi.org/10.1016/j.habitatint.2010.03.006

Siqueira-Gay, J., Gallardo, A. L. C. F., \& Giannotti, M. (2019). Integrating socioenvironmental spatial information to support housing plans. Cities, 91, 106-115. https://doi.org/10.1016/j.cities.2018.11.010

Sparshott, P.J., Darchen, S., Stjoh, D. (2018). Do sustainability-rating tools deliver the best outcomes in master-planned urban infill projects? City to the Lake experience. Australian Planner, 55, (2), 84-92. https://doi-org.elibrary.jcu.edu.au/10.1080/07293682.2019.1569077

State of the Tropics(2014). State of the TropicsReport.James Cook University, Australia. Retrieved from: http://stateofthetropics.org/the-report

Stojanovski, T. (2017). Urban Design and Multimodal Transportation-Using Urban Form and Accessibility Factors to Estimate Modal Shares and Energy Use from Transportation. Proceedings from the Annual Transport Conference at Aalborg University.

Stojanovski, T. (2019). Urban Form and Mobility Choices: Informing about Sustainable Travel Alternatives, Carbon Emissions and Energy Use from Transportation in Swedish Neighbourhoods. Sustainability, 11(2), 548. https://doi.org/10.3390/su11020548

Sun, L., Ni, J., \& Borthwick, A. G. (2010). Rapid assessment of sustainability in Mainland China. Journal of Environmental Management, 91(4), 1021-1031. https://doi.org/10.1016/j.jenvman.2009.12.015

Tran, L. (2016). An interactive method to select a set of sustainable urban development indicators. Ecological Indicators, 61, 418-427. https://doi.org/10.1016/i.ecolind.2015.09.043

Ulgiati, S. \& Zucaro, A. (2019). Challenges in Urban Metabolism: Sustainability and WellBeing in Cities. Frontier in Sustainable Cities, 1(1), pp 1-3 https://doi.org/10.3389/frsc.2019.00001 
eTropic 19.2 (2020) Special Issue: Sustainable Tropical Urbanism

Van Dijk, M. P., \& Mingshun, Z. (2005). Sustainability indices as a tool for urban managers, evidence from four medium-sized Chinese cities. Environmental Impact Assessment Review 25(6), 667-688. https://doi.org/10.1016/j.eiar.2004.10.001

Venkatesh, G., Brattebø, H., Sægrov, S., Behzadian, K., \& Kapelan, Z. (2017). Metabolismmodelling approaches to long-term sustainability assessment of urban water services. Urban Water Journal, 14(1), 11-22. https://doi.org/10.1080/1573062X.2015.1057184

Verovsek, S., Juvancic, M., \& Zupancic, T. (2016). Recognising and fostering local spatial identities using a sustainability assessment framework. Annales-Anali Za Istrske in Mediteranske Studije-Series Historia Et Sociologia, 26(3), 573-584.

Wangel, J., Wallhagen, M., Malmqvist, T., \& Finnveden, G. (2016). Certification systems for sustainable neighbourhoods: What do they really certify? Environmental Impact Assessment Review, 56, 200-213. https://doi.org/10.1016/j.eiar.2015.10.003

Wei, Y., Huang, C., Lam, P., Sha, Y., \& Feng, Y. (2015). Using urban-carrying capacity as a benchmark for sustainable urban development: an empirical study of Beijing. Sustainability, 7(3), 3244-3268. https://doi.org/10.3390/su7033244

Wilkerson, M.L., Mitchell, M., Shanahan, D., Wilson, K.A., Ives, C.D., Lovelock, C.E, Rhodes, J.R. (2018). The role of socio-economic factors in planning and managing urban ecosystem services. Ecosystem Services, 31(PA), 102-110. https://doi.org/10.1016/j.ecoser.2018.02.017

Yin, K., Wang, R., An, Q., Yao, L., \& Liang, J. (2014). Using eco-efficiency as an indicator for sustainable urban development: A case study of Chinese provincial capital cities. Ecological Indicators, 36, 665-671. https://doi.org/10.1016/j.ecolind.2013.09.003

Yoon, J., \& Park, J. (2015). Comparative analysis of material criteria in neighbourhood sustainability assessment tools and urban design guidelines: Cases of the UK, the US, Japan, and Korea. Sustainability, 7(11), 14450-14487. https://doi.org/10.3390/su71114450

Zanella, A., Camanho, A. S., \& Dias, T. G. (2015). The assessment of cities' liveability integrating human well-being and environmental impact. Annals of Operations Research, 226(1), 695-726. https://doi.org/10.1007/s10479-014-1666-7

Zhai, K., Gao, X., Zhang, Y., \& Wu, M. (2019). Perceived Sustainable Urbanization Based on Geographically Hierarchical Data Structures in Nanjing, China. Sustainability, 11(8), 2289. https://doi.org/10.3390/su11082289

Zinkernagel, R., Evans, J., \& Neij, L. (2018). Applying the SDGs to cities: business as usual or a new dawn? Sustainability, 10(9), 3201. https://doi.org/10.3390/su10093201

\section{Tables and Figures}

Table 1 Eligibility Criteria

Figure 1 A priori protocol

Figure 2 Disciplines identified in reviewed studies

Figure 3 Countries of focus and the methodologies used in the included studies

Figure 4 Articles included in the review by publication year and methods applied

Figure 5 Summary of methods applied in studies reviewed

Figure 6 Geographical distribution of the methods applied 
eTropic 19.2 (2020) Special Issue: Sustainable Tropical Urbanism

Dr Taha Chaiechi is Associate Professor of Economics in the College of Business, Law and Governance where she is also Australia Director, Centre for International Trade and Business in Asia (CITBA). Currently Taha is serving James Cook University as Expert Member on the Academic Board. Previously she has contributed to the governance and the Teaching \& Learning profile of the College in different capacities. She is also Associate Editor-in-Chief, Bulletin of Applied Economics (ABDC ranked). Taha is an expert in systematic modelling of dynamic relationships between economic, environmental and social variables. Her research attitude is holistic and inspired by issues in climate change and natural disasters, and their impacts on different economic sectors such as health, tourism, environment, energy, and cities. At the core of her research philosophy is sustainable development, and she uses the 2030 Agenda as a malleable guide throughout her research. Taha's multidisciplinary research approach has resulted in numerous collaborative projects over a broad spectrum of research topics, with the intention to enhance methodological approaches that are especially suitable for sustainability analysis. 